\title{
Molten Salt Selection Methodology for Medium Temperature Liquid Air Energy Storage Application
}

\author{
Marco Bernagozzi ${ }^{\mathrm{a}}$, Angad S. Panesar ${ }^{\mathrm{a},}$, ${ }^{,}$Robert Morgan ${ }^{\mathrm{a}}$ \\ ${ }^{a}$ Advanced Engineering Centre, School of Computing, Engineering and Mathematics, \\ University of Brighton, Lewes Road, BN2 4GJ Brighton, UK \\ *Corresponding Author: A.S.Panesar@brighton.ac.uk
}

\begin{abstract}
Power production research in the recent years is moving towards renewable energy sources with the aim to reduce $\mathrm{CO}_{2}$ emissions. A potential means to overcome the obstacles placed by the intermittent nature of the most common sustainable energy sources is represented by the Liquid Air Energy Storage (LAES) systems. In order to improve its round trip efficiency, which is currently at $50 \%$, the use of a common thermal medium for thermal storage and heat transfer fluid is considered as an effective solution. Molten salts were selected as the common thermal medium in this work, where a novel methodology for identifying and evaluating alternative mixtures is introduced. Firstly, various literature correlations were collected to form a thermo-physical property database of low melting temperature molten salts. These correlations were integrated in $\mathrm{Aspen}^{+}$by implementing a hybrid simulation technique for property estimation. These simulations were followed by a parametric analysis where 70 molten salt mixtures were evaluated in terms of thermo-physical properties by means of a performance and system index parameter. Following this process, 16 new molten salt mixtures were selected for the experimental campaign to measure their melting point temperature. As a result, two new alternative molten salt mixtures were found to have a low melting point of $95^{\circ} \mathrm{C}$ and $105^{\circ} \mathrm{C}$, whilst providing a $37 \%$ and $34 \%$ increase in the performance indicator value. Hence, the presented methodology was proven to be an effective and versatile tool in identifying alternative salt mixtures, and can be adapted for comparable applications.
\end{abstract}

Keywords: LAES; thermal energy storage; molten salt; thermo-physical properties; experimental melting point.

\section{Nomenclature}

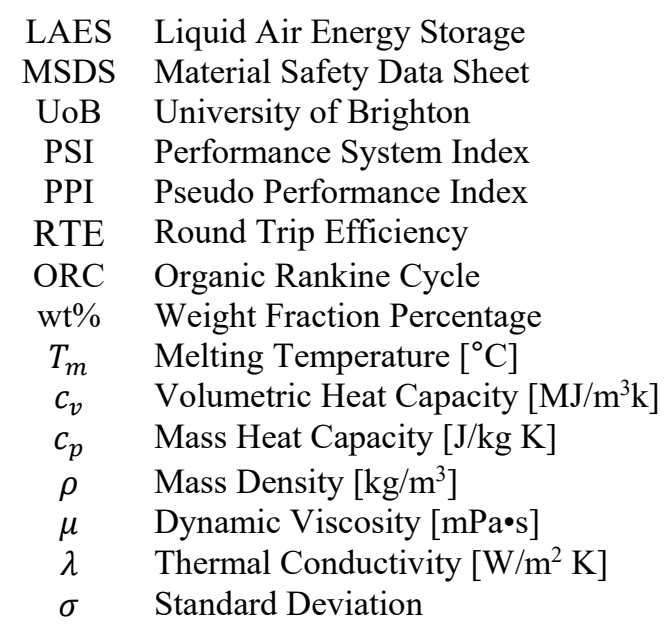

\section{Introduction}

There is an increased focus in the power generation sector to reduce $\mathrm{CO}_{2}$ emissions by utilizing less fossil fuels and more renewable energy sources, like solar and wind energy. The European Union has set a target for renewable energy to constitute $20 \%$ of the total energy produced by 2020 [1]. The very 
nature of these energy sources carries a series of intrinsic complexities in balancing the energy network, such as less flexibility and intermittent operation. Electric energy storage can partially mitigate these issues, allowing to charge energy when the production exceeds demand and to discharge it to the power grid when needed.

On grid scale applications (MW capacity), Liquid Air Energy Storage (LAES) is a novel technology gaining growing interest from the research community, due to advantages such as large volumetric energy density, no geographical dependency, negligible pollution and long operative life [2]. LAES working principle is threefold, as summarized by Figure 1: electrical energy is used to liquefy air via compression and refrigeration; cold liquefied air is stored in low pressure insulated tanks; when the grid requires additional power, liquid is drawn from the tank, heated and expanded in a turbine connected to a generator [3]. The first pilot plant $(350 \mathrm{~kW} / 2.5 \mathrm{MWh})$ was developed by the UK Company, Highview Power, and successfully passed the tests performed during 2011-2014. In 2018, Highview Power completed a grid scale demonstrator plant in Manchester, which is currently under testing. This is the only large scale LAES plant available today. Since this plant employs relatively well-established technologies, LAES currently stands at technology readiness level 7-8.

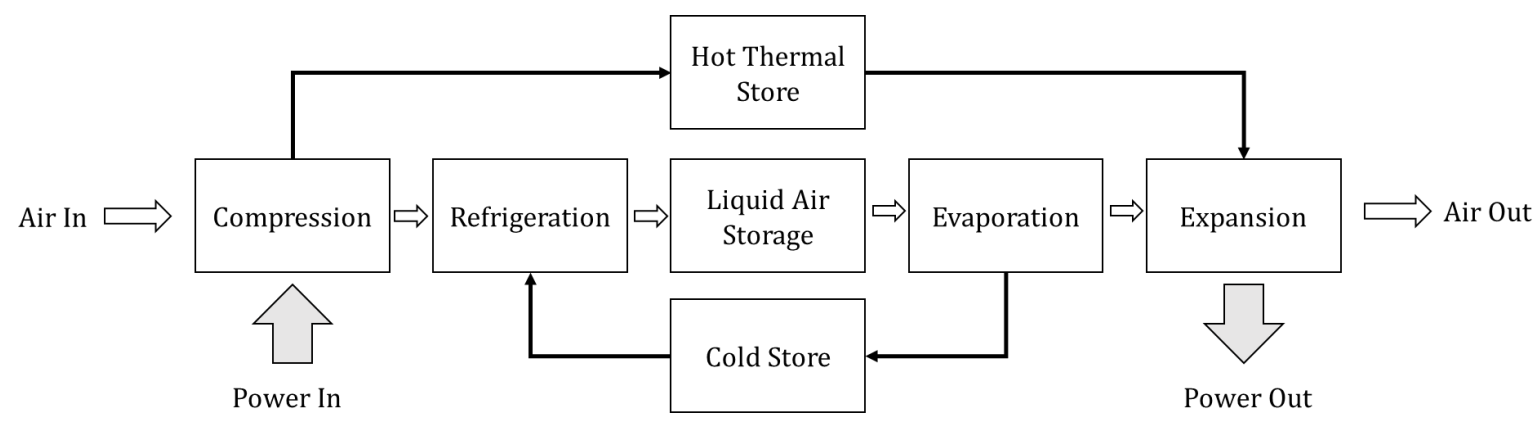

Figure 1 - LAES process diagram: The present work is focused on the efficiency improvement by utilising a common thermal medium for thermal storage and heat transfer fluid.

The main drawback of the LAES technology is its low Round Trip Efficiency (RTE), primarily attributed to the high energy consumption during the charging phase (i.e. liquefaction process), where air is compressed at relatively high pressures. Recovering heat lost during the compression process and to recover the cold energy from the liquid air discharging process (i.e. evaporation and turbine expansion process) are appealing strategies to increase RTE and the overall profitability [4]. Morgan et al. [3] firstly considered a conventional two-turbine Claude cycle for the charging process with turbines for both cold and hot store operated in parallel. The single cold turbine was replaced by a three-turbine optimized system that led to a RTE value of $60 \%$. She et al. [5] stated that there is a $20-40 \%$ excess of heat of compression that cannot be used effectively, therefore they proposed an hybrid LAES system with an Organic Rankine Cycle (ORC) and vapour compression refrigeration cycle, which lead to a RTE higher than $60 \%$. Tafone et al. [6] proposed a thermodynamic comparison between LAES equipped with ORC or absorption chiller, as ways to recover excess heat during charging, either producing additional electrical output or reducing the specific electrical consumption. The comparison resulted in favour of the ORC, which brought a maximum efficiency to 56\%. Similarly, Peng et al. [7] examined the recovery and utilization of the high-grade cold energy used in the evaporation of liquid air. They found that, with the same percentage loss of 5\%, the RTE was more affected by the cold energy loss. In fact, the RTE decrease due to heat energy loss was $1 \%$, whereas the drop due to cold energy loss was 50\%. Considering the thermal storage side of the LAES, Peng et al. [2] performed a thermodynamic characterization of a LAES system with packed beds as thermal energy store. The obtained efficiency was in the range of 50-62\% after appropriate design optimization.

The current state of the art in LAES technology is captured by the Highview's plant, which includes both High Grade Cold Store and Heat Store (Figure 1). This article specifically addresses the improvements on the Heat Store, investigating the possibility to adopt the same thermal medium for both thermal storage and heat transfer fluid, which will reduce the overall complexity and cost of the system. Such a medium should have low melting point $\left(<200^{\circ} \mathrm{C}\right)$ and appropriate thermo-physical properties, including viscosity, density, thermal conductivity and specific heat capacity. Hence, this 
work investigates suitable molten salt mixtures in a LAES system for acting both as the heat transfer fluid and the storage medium for medium-grade application $\left(<400^{\circ} \mathrm{C}\right)$.

The proposed candidate for this thermal medium are molten salts, firstly introduced by Humphrey Davy [8]. The last decade has seen increased research and development efforts in molten salts due to their appealing features such as [9]: low melting point; good thermal conductivity; high volumetric heat capacity; high boiling point; liquid over a wide operative temperature range; no undesired exothermic chemical reaction; low vapour pressure; high mass heat capacity; low viscosity; optical transparency for inspection operations; good high temperature thermal stability; insensibility to radiations. When compared against conventional coolants, they allow lower heat exchanger costs, as they provide volumetric heat capacity $25 \%$ higher than pressurised water and five times higher than liquid sodium [9].

Molten salts do not reduce the sustainability benefits of the LAES system, as their life cycle has been proven to be longer than the operative life of comparable systems. For instance, Piemonte et al. [10] assessed the environmental impact of a molten salt solar plant and found it preferable with respect to other conventional solutions such as oil and gas power plants. Moreover, Adeoye et al. [11] compared the life cycle assessment for two thermal energy storage technologies: concrete and molten salt. Results showed that, molten salt have less negative environmental impact as the thermal energy storage option. There are two types of molten salt storage [12]: direct, where the molten salt heats up directly the steam sent to the turbine for energy conversion; indirect, where the molten salt is used as storage and it heats up the thermal oil that subsequently will heat up the steam for energy conversion. Recent research is investigating low melting point temperature salts in order to mitigate issues linked to heat tracing mechanism, thermal insulation, emergency response system and to reduce the risk of freezing inside the pipes [13]. All these factors increase the initial capital investment as well as the running costs.

The present work is focused on the identification of tailored molten salt candidates for medium-grade heat recovery in a LAES system. Published literature was utilised to select the 5 baseline commercial salt mixtures with low melting point. Utilising published experimental data, a simulation procedure to evaluate the thermo-physical properties of mixture compositions is introduced. Following a thermophysical parametric analysis on 70 salt mixtures, 16 potential new salt mixtures were considered for experimental identification of melting point. As a result, 2 new alternative salt mixtures were identified to provide improved performance index value compared to the baseline mixtures.

Figure 2 presents the methodology overview of the present work, which is reflected by the structure of this paper. The first phase resulted in the creation of a University of Brighton database (herein referred as UoB Database) of pure and molten salt mixtures for simulations in Aspen ${ }^{+}$. Following a two-step screening process, the second phase evaluated alternative salt mixtures using parametric analysis, and the proposed performance and system index. The final stage contributed to the identification of two potential new salt mixtures using the synoptic maps, as a result of the experimental melting point campaign and the feasibility normalisation through a numerical indicator, pseudo performance index. 


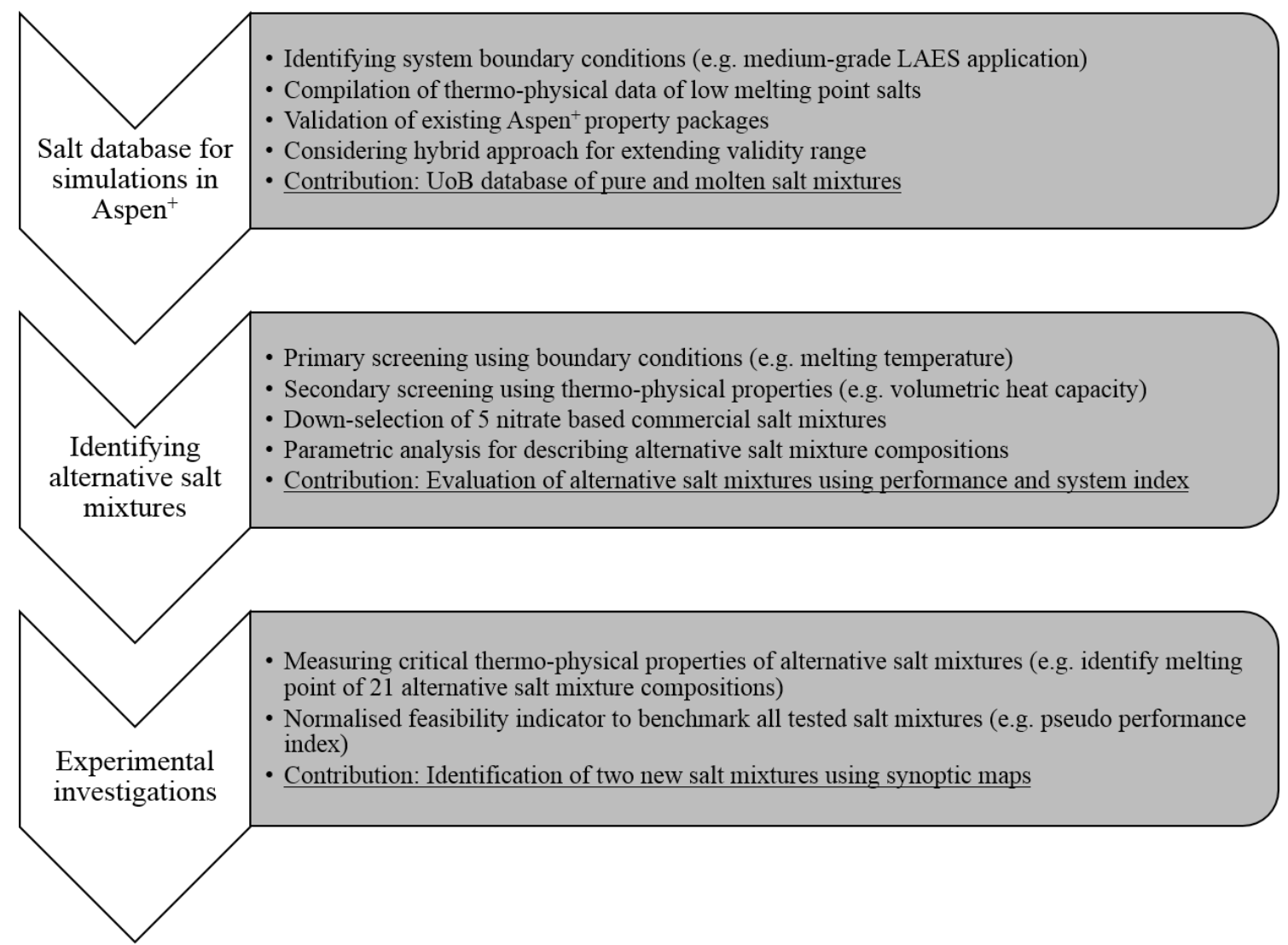

Figure 2 - Flow chart of the methodology for identifying and evaluating alternative salt mixtures. Resulting contributions from the present investigation are underlined.

\section{Molten Salt Database}

As pointed out by Nunes et al. [8] there exist discrepancies in the physical property values for the common pure molten salts as well as mixtures published over the years. This is not only in relation to their absolute values, but also their variation with temperature. Hence, there was the need for an extensive and intensive literature review to gain confidence in the property data expected to be used for mixture simulations.

The examined case of the LAES application resulted in two boundary conditions. Firstly, relating to the melting point/lowest operating temperature $\left(\leq 200^{\circ} \mathrm{C}\right)$, and secondly, relating to the highest operating/degradation temperature $\left(\geq 400^{\circ} \mathrm{C}\right)$. Table 1 and Table 2 presents the melting temperature for pure salts and mixture salts, respectively. Table 2 focuses on the low melting point salt mixtures, due to the melting point boundary condition. Table 2 demonstrates how the majority of low melting temperature molten salts are constituted by the nitrate family, which became the main focus of the present investigation, as further explained in section 3.

Table 1 - Pure salts melting temperature data following the literature review. Only the salts forming the mixtures investigated in this work have been reported.

\begin{tabular}{llrl}
\hline Pure Molten Salts & Formula & $\boldsymbol{T}_{\text {melt }}\left[{ }^{\circ} \mathrm{C}\right]$ & Ref \\
\hline Aluminium Chloride & $\mathrm{AlCl} 3$ & 192 & {$[16]$} \\
Lithium Nitrate & $\mathrm{LiNO} 3$ & 253 & {$[17]$} \\
Sodium Nitrite & $\mathrm{NaNO} 2$ & 271 & {$[18]$} \\
Zinc Chloride & $\mathrm{ZnCl} 2$ & 283 & {$[16]$} \\
Sodium Nitrate & $\mathrm{NaNO3}$ & 307 & {$[17]$} \\
Rubidium Nitrate & $\mathrm{RbNO3}$ & 312 & {$[17]$} \\
Sodium Hydroxide & $\mathrm{NaOH}$ & 318 & {$[19]$} \\
Potassium Nitrate & $\mathrm{KNO} 3$ & 335 & {$[17]$} \\
Potassium Hydroxide & $\mathrm{KOH}$ & 360 & {$[20]$}
\end{tabular}




\begin{tabular}{llrl} 
Calcium Nitrate & $\mathrm{Ca}(\mathrm{NO} 3) 2$ & 561 & {$[20]$} \\
Potassium Chloride & $\mathrm{KCl}$ & 770 & {$[16]$} \\
Sodium Chloride & $\mathrm{NaCl}$ & 802 & {$[16]$} \\
\hline
\end{tabular}

Table 2 - Salt mixtures melting temperature data following the literature review.

\begin{tabular}{|c|c|c|c|}
\hline Molten Salt Mixtures (comp wt\%) & Name & $T_{\text {melt }}\left[{ }^{\circ} \mathrm{C}\right]$ & Ref \\
\hline $\begin{array}{l}\text { KNO3-NH4NO3-AgNO3 } \\
(20-47-33)\end{array}$ & & 52 & {$[21]$} \\
\hline KNO3-KNO2-LiCl-LiNO3-Ca(NO3)2-NaNO2 & Saltstream 300 & 56 & \\
\hline LiNO3-NaNO3-KNO3-CsNO3-Ca(NO3)2 & Saltstream 500 & 65 & \\
\hline $\begin{array}{l}\text { LiNO3-Ca(NO3)2-NaNO2-KNO2 } \\
(24.6-13.6-16.8-45)\end{array}$ & CaLiNaK & 72 & {$[12]$} \\
\hline $\begin{array}{l}\text { KNO3-LiNO3-Ca(NO3)2 } \\
(50-80)-(0-25)-(10-45)\end{array}$ & & 80 & {$[22]$} \\
\hline $\begin{array}{l}\mathrm{KCl}+\mathrm{AlCl} 3+\mathrm{NaCl} \\
(11-78-11)\end{array}$ & & 88.9 & {$[16]$} \\
\hline $\begin{array}{l}\text { KNO3-NaNO3-LiNO3-Ca(NO3)2 } \\
(54.54-9.09-18.18-18.18)\end{array}$ & & 90 & {$[13]$} \\
\hline $\begin{array}{l}\text { KNO3-LiNO3-NH4NO3 } \\
(24-25-51)\end{array}$ & & 92 & {$[21]$} \\
\hline $\begin{array}{l}\mathrm{LiNO} 3-\mathrm{NaNO} 3-\mathrm{KNO} 3-\mathrm{CsNO} 3-\mathrm{Ca}(\mathrm{NO} 3) 2 \\
(8-6-23-44-19)\end{array}$ & & 95 & {$[14]$} \\
\hline $\begin{array}{l}\text { NaNO3-KNO3-LiNO3-Ca(NO3)2 } \\
(9-18)-(40-52)-(13-21)-(20-27)\end{array}$ & Sandia Mix & 95 & {$[22]$} \\
\hline $\begin{array}{l}\text { NaNO3-KNO3-LiNO3-NaNO2 } \\
(14.2-50.5-17.5-17.8)\end{array}$ & Quaternary & 99 & {$[16]$} \\
\hline $\begin{array}{l}\text { LiNO3-NaNO3-KNO3-Sr(NO3)2 } \\
(29-17-49.4-4.6)\end{array}$ & & 105 & {$[17]$} \\
\hline $\begin{array}{l}\mathrm{NaCl}-\mathrm{AlCl} 3 \\
(20-80)\end{array}$ & & 108 & {$[16]$} \\
\hline $\begin{array}{l}\text { KNO3-CaNO3-LiNO3 } \\
(21-18-61)\end{array}$ & & 117 & {$[21]$} \\
\hline NaNO3-KNO3-Ca(NO3)2 & Saltstream Xl & 120 & \\
\hline $\begin{array}{l}\text { NaNO3-KNO3-LiNO3 } \\
(18-52-30)\end{array}$ & $\mathrm{LiNaK}$ & 120 & {$[12]$} \\
\hline $\begin{array}{l}\text { NaNO3-KNO3-Ca(NO3)2 } \\
(7-45-48)\end{array}$ & HITEC XL & 120 & {$[22]$} \\
\hline $\begin{array}{l}\mathrm{KCl}-\mathrm{AlCl} 3 \\
(22-78)\end{array}$ & & 128 & {$[16]$} \\
\hline $\begin{array}{l}\text { NaNO3-KNO3-LiNO3 } \\
(28-52-20)\end{array}$ & $\mathrm{LiNaK}$ & 130 & {$[22]$} \\
\hline $\begin{array}{l}\text { KNO3-LiNO3 } \\
(68-32)\end{array}$ & $\mathrm{LiK}$ & 133 & [23] \\
\hline $\begin{array}{l}\mathrm{NaNO} 3-\mathrm{KNO} 3-\mathrm{Ca}(\mathrm{NO} 3) 2 \\
(15-42-43)\end{array}$ & & 133 & [21] \\
\hline $\begin{array}{l}\text { NaNO3-NaNO2-KNO3 } \\
(7-40-53)\end{array}$ & HITEC & 142 & [9] \\
\hline $\begin{array}{l}\mathrm{NaOH}-\mathrm{KOH} \\
(42-58)\end{array}$ & & 170 & [17] \\
\hline $\begin{array}{l}\text { NaNO3-KNO3 } \\
(60-40)\end{array}$ & Solar Salt & 222 & [9] \\
\hline
\end{tabular}

To satisfy the second boundary condition, the expected peak stagnation hotspot temperature for the salts must be below the thermal degradation limit, otherwise this will adversely impact the overall system efficiency and the operative life of the salts. Degradation results for nitrate based salts in mass loss with gas evolution were presented by Bauer et al. [24]. A mass loss of $<1 \%$ was reported for temperatures in the region of $500^{\circ} \mathrm{C}$. Due to the thermal degradation boundary condition, Table 3 focuses on salt mixtures with reported degradation temperature above $400^{\circ} \mathrm{C}$. It is evident that, the majority of the salt mixtures presented a safety margin of $\geq 80^{\circ} \mathrm{C}$.

Table 3 - Salt mixtures degradation temperature data following the literature review.

\begin{tabular}{llrr}
\hline Formula & Name & $\boldsymbol{T}_{\boldsymbol{d e g}}\left[{ }^{\circ} \mathrm{C}\right]$ & Ref \\
\hline KNO3-KNO2-LiCl-LiNO3-Ca(NO3)2-NaNO2 & Saltstream 300 & 300 & \\
NaNO3-KNO3-LiNO3-NaNO2 & Quaternary & 430 & {$[22]$} \\
\hline
\end{tabular}




\begin{tabular}{llll}
\hline $\begin{array}{l}(14.2-50.5-17.5-17.8) \\
\text { Ca(NO3)2-NaNO3-KNO3 } \\
(30-20-50)\end{array}$ & & 480 & {$[12]$} \\
LiNO3-NaNO3-KNO3-CsNO3-Ca(NO3)2 & Saltstream 500 & 500 & \\
$\begin{array}{l}\text { NaNO3-KNO3-Ca(NO3)2 } \\
(7-45-48)\end{array}$ & HITEC XL & 500 & {$[22]$} \\
$\begin{array}{l}\text { KNO3-LiNO3-Ca(NO3)2 } \\
(50-80)-(0-25)-(10-45)\end{array}$ & & 500 & {$[22]$} \\
$\begin{array}{l}\text { NaNO3-KNO3-LiNO3-Ca(NO3)2 } \\
(9-18)-(40-52)-(13-21)-(20-27)\end{array}$ & & 500 & {$[22]$} \\
$\begin{array}{l}\text { Ca(NO3)2-NaNO3-KNO3 } \\
(20-30-50)\end{array}$ & Sandia Mix & 505 & {$[12]$} \\
$\begin{array}{l}\text { LiNO3-Ca(NO3)2-NaNO2-KNO2 } \\
(24.6-13.6-16.8-45)\end{array}$ & & 510 & {$[12]$} \\
$\begin{array}{l}\text { KNO3-NaNO3-NaNO2 } \\
(53-7-40)\end{array}$ & CaLiNaK & 550 & {$[25]$} \\
$\begin{array}{l}\text { NaNO3-KNO3-LiNO3 } \\
(18-52-30)\end{array}$ & HITEC & 550 & {$[12]$} \\
$\begin{array}{l}\text { NaNO3-KNO3 } \\
(60-40)\end{array}$ & LiNaK & 600 & {$[25]$} \\
$\begin{array}{l}\text { NaNO3-KNO3-LiNO3 } \\
(28-52-20)\end{array}$ & Solar Salt & 600 & {$[22]$} \\
NaNOI3-KNO3-Ca(NO3)2 & & 700 & \\
\hline
\end{tabular}

For pure and mixture salts identified in Table 1 and Table 2, a detailed database was created using the thermo-physical properties summarised in Table 4 to Table 8 . Following adherence to the boundary conditions set by the LAES case, a screening process utilising selected thermo-physical properties was considered. The database was then employed during the screening process, as later explained in Section 3. Due to a strong influence on the system viability, the objective functions were:

- Increased volumetric heat capacity, defined as $c_{v}=\rho \cdot c_{p}$, as it is inversely proportional to the size of vessels and heat exchangers;

- Increased thermal conductivity, as it is directly proportional to the convective heat transfer;

- Decreased salt cost, as a thermal storage system utilising molten salts should be economically competitive with respect to thermal oil alternative;

- Decreased dynamic viscosity, as it is inversely proportional to pressure drop, which is particularly important in the heat exchanger.

Table 4 - Mass heat capacity data for pure molten salt and mixtures following the literature review. $\left(T[\mathrm{~K}], t\left[{ }^{\circ} \mathrm{C}\right]\right)$

\begin{tabular}{|c|c|c|c|}
\hline Salt Name & $\begin{array}{l}\text { Validity } \\
\text { Range }[\mathrm{K}]\end{array}$ & Mass Heat Capacity $[\mathrm{J} / \mathrm{kgK}]$ & Ref \\
\hline $\mathrm{NaNO} 3$ & $\begin{array}{l}334-493 \\
586-653\end{array}$ & $\begin{array}{c}10^{3}\left(3.15-1.186 \cdot 10^{-2} T++1.807 \cdot 10^{-5} T^{2}\right) \\
10^{3}\left(1.676+1.282 \cdot 10^{-5} T\right)\end{array}$ & [17] \\
\hline KNO3 & $\begin{array}{l}334-400 \\
423-600 \\
620-733\end{array}$ & $\begin{array}{c}10^{3}\left(0.326-1.91 \cdot 10^{-3} T\right) \\
10^{3}\left(2.442-5.682 \cdot 10^{-3} T+6.628 \cdot 10^{-6} T^{2}\right) \\
10^{3}\left(1.417-4.678 \cdot 10^{-5} T\right)\end{array}$ & [17] \\
\hline $\mathrm{NaNO} 2$ & $450-550$ & $\left(1469-5.75 T+6.17 \cdot 10^{-3} T^{2}\right) \cdot M_{m}$ & [26] \\
\hline $\begin{array}{l}\mathrm{Ca}(\mathrm{NO} 3) 2 * 4 \\
\mathrm{H} 20\end{array}$ & 234-312 & $236-0.06 T+14.9 \cdot 10^{-4} T^{2}$ & {$[27]$} \\
\hline LiNO3 & $\begin{array}{l}334-493 \\
540-653\end{array}$ & $\begin{array}{l}10^{3}\left(0.585+2.182 \cdot 10^{-3} T\right) \\
10^{3}\left(1.681+6.389 \cdot 10^{-4} T\right)\end{array}$ & [17] \\
\hline $\mathrm{Ca}(\mathrm{NO} 3) 2$ & $550-655$ & $1.2073 T-9.0244$ & [28] \\
\hline $\mathrm{AlCl3}$ & $466-1500$ & 941.2 & [16] \\
\hline $\mathrm{NaCl}$ & $1074-2500$ & $\begin{array}{c}-42.4478+113.526 \cdot 10^{-3} T-43.6466 \cdot\left(10^{-3} T\right)^{2}+5.89663 \cdot\left(10^{-3} T\right)^{3} \\
+39.1386 /\left(10^{-3} T\right)^{2}\end{array}$ & [16] \\
\hline $\mathrm{NaOH}$ & $330-505$ & $10^{3}\left(1.028+1.443 \cdot 10^{-3} T\right)$ & [17] \\
\hline $\mathrm{KCl}$ & $1070-1170$ & 987.24 & [16] \\
\hline Solar Salt & & $1396.044+0.172 t$ & [9] \\
\hline HITEC & $153-503$ & $\begin{array}{c}5806-10.833 t+7.2413 \cdot 10^{-3} t^{2} \\
1560\end{array}$ & $\begin{array}{l}{[29]} \\
{[9]}\end{array}$ \\
\hline $\mathrm{LiNaK}$ & $373-673$ & 1600 & [12] \\
\hline CaLiNaK & $373-673$ & 1650 & [12] \\
\hline HITEC XL & $423-723$ & $1.903-0.69 \cdot 10^{-4} t$ & [12] \\
\hline
\end{tabular}




\begin{tabular}{cccc} 
& $403-493$ & 1430 \\
& $423-593$ & 1480 \\
& $393-793$ & $-0.325 t+1539$ \\
& $330-360$ & $10^{3}\left(0.905+1.124 \cdot 10^{-3} T\right)$ & \\
$\mathrm{NaOH}-\mathrm{KOH}$ & $365-430$ & $10^{3}\left(0.435+2.451 \cdot 10^{-3} T\right)$ & {$[17]$} \\
& $470-575$ & $10^{3}\left(1.8+0.023 \cdot 10^{-3} T\right)$ & \\
\hline
\end{tabular}

Table 5 - Density data for pure molten salt and mixtures following the literature review. $\left(T[\mathrm{~K}], t\left[{ }^{\circ} \mathrm{C}\right]\right)$.

\begin{tabular}{lccc}
\hline Salt Name & Validity Range $[\mathrm{K}]$ & Mass Density $\left[\mathrm{kg} / \mathrm{m}^{3}\right]$ & Ref \\
\hline $\mathrm{NaNO3}$ & $420-871$ & $-0.7582 T+2328.4198$ & {$[29]$} \\
$\mathrm{KNO3}$ & $420-871$ & $-0.7332 T+2318.0289$ & {$[29]$} \\
$\mathrm{NaNO} 2$ & $570-723$ & $10^{3}\left(2.26-0.746 \cdot 10^{-3} T\right)$ & {$[30]$} \\
$\mathrm{Ca}(\mathrm{NO} 3) 2 * 4 \mathrm{H} 20$ & $572-646$ & $1749.5-0.83408 t$ & {$[31]$} \\
$\mathrm{LiNO3}$ & $420-871$ & $-0.551 T+2071.3353$ & {$[29]$} \\
& $465-560$ & $10^{3}\left(3.7660038-1.3346 \cdot 10^{-2} T\right.$ & {$[16]$} \\
$\mathrm{AlCl} 3$ & & $\left.+2.7622 \cdot 10^{-5} T^{2}-2.2331268 \cdot 10^{-8} T^{3}\right)$ & {$[29]$} \\
& $1076-1303$ & $2.1393-0.543 \cdot 10^{-3} T$ & {$[16]$} \\
$\mathrm{NaCl}$ & $1080-1290$ & $10^{3}\left(2.1393-5.43 \cdot 10^{-4} T\right)$ & {$[29]$} \\
$\mathrm{NaOH}$ & $593-723$ & $2.068-0.4784 \cdot 10^{-3} T$ & {$[16]$} \\
$\mathrm{KCl}$ & $1060-1200$ & $10^{3}\left(2.1359-5.831 \cdot 10^{-4} T\right)$ & {$[9]$} \\
& $573-873$ & $2263.628-0.636 T$ & {$[12]$} \\
$\mathrm{Solar} \mathrm{Salt}$ & $420-871$ & $-0.6426 T+2267.9732$ & {$[30]$} \\
& $197-597$ & $2293.6-0.7497 T$ & {$[9]$} \\
$\mathrm{HITEC}$ & $448-773$ & $2279.799-0.7324 T$ & {$[12]$} \\
$\mathrm{LiNaK}$ & $423-723$ & $2077-0.735 t$ & {$[12]$} \\
$\mathrm{CaLiNaK}$ & $373-673$ & $2084-0.732 t$ & {$[12]$} \\
$\mathrm{HITEC} \mathrm{XL}$ & $423-873$ & $-0.62126 t+2170.06296$ & {$[16]$} \\
$\mathrm{NaCl}-\mathrm{AlCl} 3$ & $440-540$ & $2034-0.866 T$ & {$[16]$} \\
$\mathrm{KCl}-\mathrm{AlCl} 3$ & $500-780$ & $1988.9-0.7901 T$ & \\
\hline
\end{tabular}

Table 6 - Cost data for pure molten salt and mixtures following the literature review (Synthetic oil is added for comparison purposes).

\begin{tabular}{lrr}
\hline Salts Name & Cost $[\$ / \mathrm{kg}]$ & Ref \\
\hline NaNO3 & 0.41 & {$[17]$} \\
& 0.2 & \\
KNO3 & 0.62 & {$[17]$} \\
NaNO2 & 0.3 & \\
LiNO3 & 0.362 & \\
& 4.32 & {$[32]$} \\
Ca(NO3)2 & 3.5 & {$[21]$} \\
NaCl & 1.43 & {$[17]$} \\
NaOH & 0.16 & {$[32]$} \\
KCl & 0.15 & {$[17]$} \\
KOH & 0.508 & \\
MgCl2 & 0.58 & \\
ZnCl2 & 1 & {$[17]$} \\
MgCl2 & 0.36 & \\
LiCl & 1.3 & \\
\hline Solar Salt & 0.29 & \\
HITEC & 11 & \\
NaNO3-KNO3-LiNO3 & 0.49 & {$[17]$} \\
(28-52-20) & 1.92 & {$[17]$} \\
HITEC XL & 0.93 & {$[22]$} \\
KNO3-LiNO3-Ca(NO3)2 & 1.1 & {$[22]$} \\
(50-80)-(0-25)-(10-45) & 1.19 & {$[17]$} \\
Sandia Mix & 1.1 & {$[22]$} \\
Saltstream 300 & 0.7 & {$[22]$} \\
Saltstream 500 & 0.72 & {$[22]$} \\
Saltstream Xl & 10 & \\
Synthetic oil & 124 & \\
\hline
\end{tabular}


Table 7 - Viscosity data for pure molten salt and mixtures following the literature review. $\left(T[\mathrm{~K}], t\left[{ }^{\circ} \mathrm{C}\right]\right)$.

\begin{tabular}{|c|c|c|c|}
\hline Salt Name & $\begin{array}{c}\text { Validity } \\
\text { Range [K] }\end{array}$ & Dynamic Viscosity [mPa*s] & Ref \\
\hline $\mathrm{NaNO}_{3}$ & $590-750$ & $1.2748 T-2.1478$ & [33] \\
\hline KNO3 & $530-750$ & $-0.0000002153 T^{3}+0.0004664 T^{2}-0.3433 T+87.3479$ & [33] \\
\hline $\mathrm{NaNO} 2$ & $560-580$ & $610.946-298.133 \cdot 10^{-2} T+48.7657 \cdot 10^{-4} T^{2}-266.247 \cdot 10^{-8} T^{3}$ & [30] \\
\hline LiNO3 & $530-750$ & $-0.0000004649 T^{3}+0.0009595 T^{2}-0.6650 T+156.9159$ & [29] \\
\hline $\mathrm{AlCl} 3$ & $465-560$ & $3.2146-9.6606 \cdot 10^{-3} T+7.4554 \cdot 10^{-6} T^{2}$ & [16] \\
\hline \multirow[b]{2}{*}{$\mathrm{NaCl}$} & $1060-1200$ & $81.9007-18.5538 \cdot 10^{-2} T+14.2786 \cdot 10^{-4} T^{2}-3.70073 \cdot 10^{-8} T^{3}$ & [30] \\
\hline & $1090-1200$ & $0.08931 e^{\frac{5248.1}{1.98716 T}}$ & [16] \\
\hline $\mathrm{NaOH}$ & $630-820$ & $164.771-61.4833 \cdot 10^{-2} T+7.8034 \cdot 10^{-4} T^{2}-33.334 \cdot 10^{-8} T^{3}$ & [30] \\
\hline $\mathrm{KCl}$ & $1070-1170$ & $0.0732 e^{\frac{5601.7}{1.98716 T}}$ & [16] \\
\hline Solar Salt & $573-873$ & $0.075439-2.77 \cdot 10^{-4} t+3.49 \cdot 10^{-7} t^{2}-1.474 \cdot 10^{-10} t^{3}$ & [9] \\
\hline \multirow{2}{*}{ HITEC } & $420-710$ & $0.4737-2.297 \cdot 10^{-3} T+3.731 \cdot 10^{-6} T^{2}-2.019 \cdot 10^{-9} T^{3}$ & [30] \\
\hline & $525-773$ & $e^{-4.343-2.0143 \cdot(\ln t-5.011)}$ & {$[8]$} \\
\hline $\mathrm{LiNaK}$ & $373-773$ & $1330000 t^{-2.24}$ & [12] \\
\hline $\mathrm{CaLiNaK}$ & $373-673$ & $569000000 t^{-3.32}$ & [12] \\
\hline HITEC XL & $373-773$ & $137214497 t^{-3.36406}$ & [12] \\
\hline $\mathrm{NaCl}-\mathrm{AlCl} 3$ & $450-570$ & $10^{-3}\left(4.9477 e^{\frac{3850.2}{1.98716 T}}\right)$ & {$[16]$} \\
\hline
\end{tabular}

Table 8 - Thermal conductivity data for pure molten salt and mixtures following the literature review. (T $\left.[\mathrm{K}], t\left[{ }^{\circ} \mathrm{C}\right]\right)$.

\begin{tabular}{llcr}
\hline Salts Name & Validity Range $[\mathrm{K}]$ & Thermal Conductivity $[\mathrm{W} / \mathrm{m} \mathrm{K}]$ & Ref \\
\hline $\mathrm{NaNO3}$ & $583-673$ & $0.56415-0.000155547 T$ & {$[34]$} \\
$\mathrm{KNO} 3$ & $616-440$ & $0.51586-0.000291354 T$ & {$[34]$} \\
$\mathrm{NaNO} 2$ & $286-325$ & $1.1366 T-0.0701$ & {$[17]$} \\
$\mathrm{LiNO3}$ & $320-673$ & $2.1048 T-0.549$ & {$[17]$} \\
$\mathrm{Ca}(\mathrm{NO} 3) 2$ & $300-400$ & $1.3337 T-0.1168$ & {$[34]$} \\
$\mathrm{NaCl}$ & $1100-1200$ & $\left(1.868 \cdot+4.73 \cdot 10^{-7} T\right) \cdot 418.4$ & {$[16]$} \\
$\mathrm{NaOH}$ & & 0.88 & {$[18]$} \\
$\mathrm{KCl}$ & $1050-1200$ & 0.92 & {$[18]$} \\
$\mathrm{KNO} 3$ & $343-427$ & $\left(-23.43 \cdot 10^{-4}+4.103 \cdot 10^{-6} T\right) \cdot 418.4$ & {$[16]$} \\
$\mathrm{Solar} \mathrm{Salt}$ & $251-398$ & $1.2452 T-0.095$ & {$[17]$} \\
$\mathrm{HITEC}$ & $251-398$ & $1.5867 T-0.2667$ & {$[17]$} \\
LiNaK & $422-727$ & $1.5867 T-0.2657$ & {$[17]$} \\
$\mathrm{CaLiNaK}$ & & $-0.00033 t+0.44885$ & {$[12]$} \\
$\mathrm{HITEC} \mathrm{XL}$ & & 0.5 & {$[12]$} \\
NaCl-AlCl3 & & 0.52 & {$[12]$} \\
\hline
\end{tabular}

\section{Molten Salt Thermo-physical Property Simulations}

\subsection{Screening Process}

The aim of the presented work was to investigate potential new molten salt mixtures for the considered LAES case. As highlighted in Section 2, it was evident that there is a fragmentation in the published salt data. Hence, it was deemed appropriate to verify the property package of the simulation platform chosen originally (Aspen HYSYS), against the University of Brighton (UoB) database presented in Section 2. However, errors in excess of $30 \%$ were found, regardless of the used property package.

In order to mitigate this error, Aspen ${ }^{+}$was instead chosen as the simulation platform, as it allowed manual insertion of the physical property data. The properties of the single salts reported in literature from experimental data were all reproduced with negligible error $(<1 \%)$ over the interested temperature range $\left(100-400^{\circ} \mathrm{C}\right)$. If the validity range of the published data was insufficient, then firstly, an interpolation between different published data was conducted, and secondly, this was complemented with utilising the best matching existing property package in Aspen ${ }^{+}$. This hybrid two-step process resulted in the contribution of the present work to the UoB database, as captured in Table 9. 


\section{Mass Heat Capacity $\mathrm{NaNO}_{2}$}

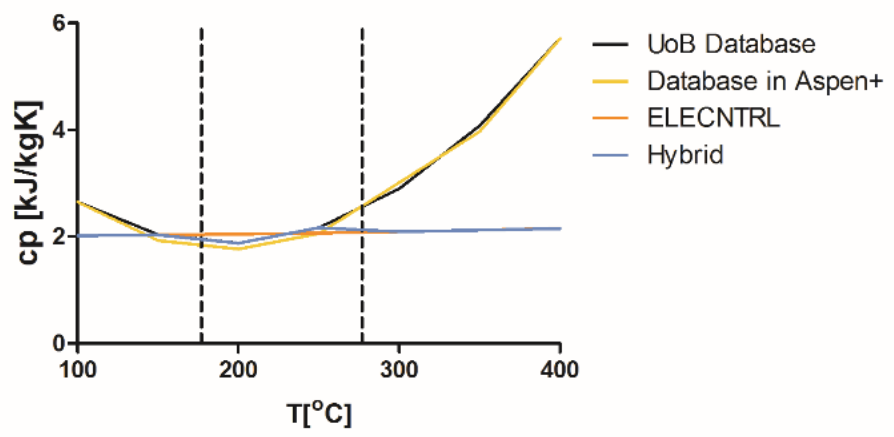

Figure 3 - Example of the hybrid approach for the single salt $\mathrm{NaNO}_{2}$. In this are presented the literature published correlation (black), between its validity temperature range (dashed vertical lines); its implementation on Aspen ${ }^{+}$ (yellow); data from the ELECNTRL property package (orange); result of the hybrid approach introduced in this work (blue).

An example of this process is illustrated in Figure 3. The black curve represents the polynomial function derived from the UoB database, in this case Ref. [26]; the yellow curve represents this data implemented directly in Aspen ${ }^{+}\left(\right.$Database in Aspen ${ }^{+}$; the orange curve represents the ELECNTRL results in Aspen ${ }^{+}$, which was the best matching property package giving an error of $<5 \%$; the blue curve represents the hybrid interpolation between ELECNTRL and the UoB database. It is evident how the UoB database is diverging outside the published validity temperature range (dashed black lines). Therefore, the hybrid approach offered a viable compromise complementing the validity temperature range of the published data with the best matching property package from Aspen ${ }^{+}$. As a result of this hybrid approach, four new correlations for pure salt were added to the UoB database, as presented in Table 9.

Table 9 - New contribution to the UoB database for pure salts as a result of the hybrid approach introduced in this work.

\begin{tabular}{|c|c|c|c|}
\hline $\begin{array}{l}\text { Salt } \\
\text { Name }\end{array}$ & $\begin{array}{l}\text { Validity } \\
\text { Range }\left[{ }^{\circ} \mathrm{C}\right]\end{array}$ & Correlation & $\overline{\mathrm{R}^{2}}$ \\
\hline KNO3 & $100-400$ & $\begin{array}{c}c_{p}=-7.208 \cdot 10^{-14} t^{6}+1.095 \cdot 10^{-10} 6 t^{5}-6.630 \cdot 10^{-8} t^{4}+2.039 \cdot 10^{-5} t^{3} \\
-3.345 \cdot 10^{-3} t^{2}+0.277 t-7.747\end{array}$ & 0.999 \\
\hline NaNO3 & $100-400$ & $\begin{array}{c}c_{p}=-6.392 \cdot 10^{-12} t^{5}+8.421 \cdot 10^{-9} t^{4}-4.214 \cdot 10^{-6} t^{3}+9.859 \cdot 10^{-4} t^{2} \\
-0.105 \cdot 10^{-1} t+5.198\end{array}$ & 0.999 \\
\hline NaNO2 & $100-400$ & $\begin{array}{c}c_{p}=3.256 \cdot 10^{-12} t^{5}-2.719 \cdot 10^{-9} t^{4}+4.130 \cdot 10^{-7} t^{3}+1.851 \cdot 10^{-4} t^{2} \\
-6.084 \cdot 10^{-2} t+6.711 \\
\mu=2.502 \cdot 10^{-11} t^{5}-3.608 \cdot 10^{-8} t^{4}+1.934 \cdot 10^{-5} t^{3}-4.593 \cdot 10^{-3} t^{2} \\
+4.072 \cdot 10^{-1} t+3.517\end{array}$ & 0.951 \\
\hline
\end{tabular}

For modelling salt mixtures, only the pure salt properties were imposed in Aspen $^{+}$from the UoB database. Due to existing published data on the common salt mixtures, it was possible to verify that Aspen $^{+}$predicted the properties with a low error (7-12\%). In Figure 4, the yellow curves (modelling) were obtained by mixing the pure salts using the UoB database in Aspen ${ }^{+}$with the corresponding mass fractions.

If significant inaccuracies in mixture property predictions were encountered due to the validity range of the published data then the hybrid approach correlations provided in Table 9 were utilized. This can be noted in the HITEC example in Figure 4a, where the modelling results for mass heat capacity diverge after $250^{\circ} \mathrm{C}$, this was due to the skewness in the published correlation for sodium nitrite shown in Figure 3. Hence, the hybrid approach, shown by the blue curve (Figure $4 \mathrm{a}$ and Figure $4 \mathrm{~b}$ ), enabled a sensible improvement in property estimation results for the salt mixtures. This hybrid approach gave reasonable results for mixture modelling, with errors of less than $7 \%$ for mass heat capacity, $12 \%$ for viscosity, $13 \%$ for thermal conductivity and $0.4 \%$ for density. 
(a) Mass Heat Capacity

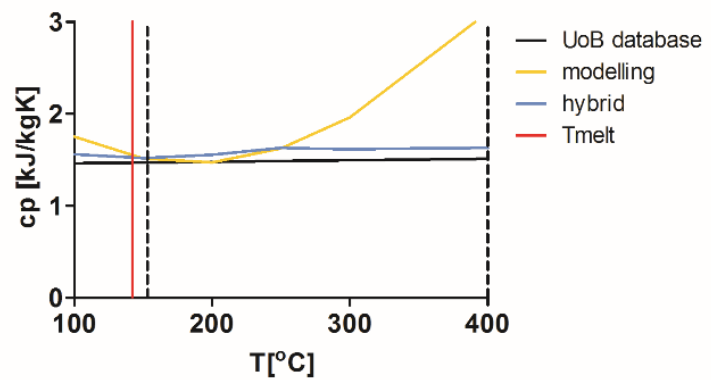

(c) Thermal Conductivity

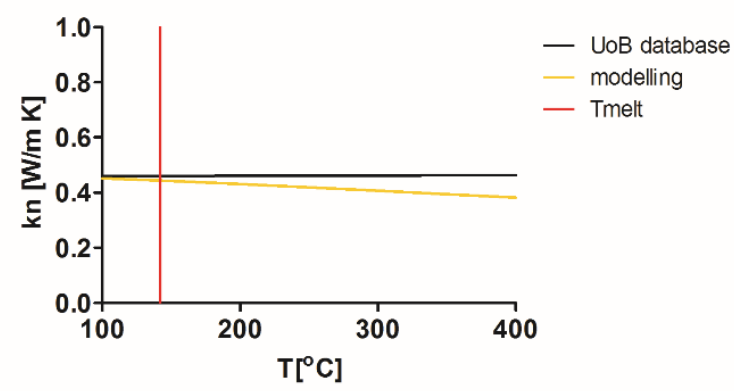

(b) Viscosity

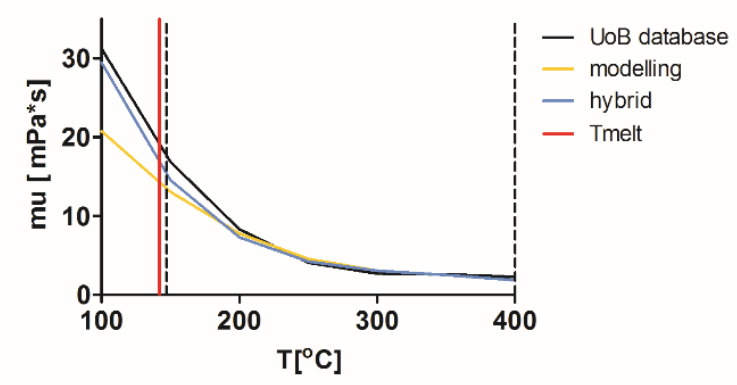

(d) Density

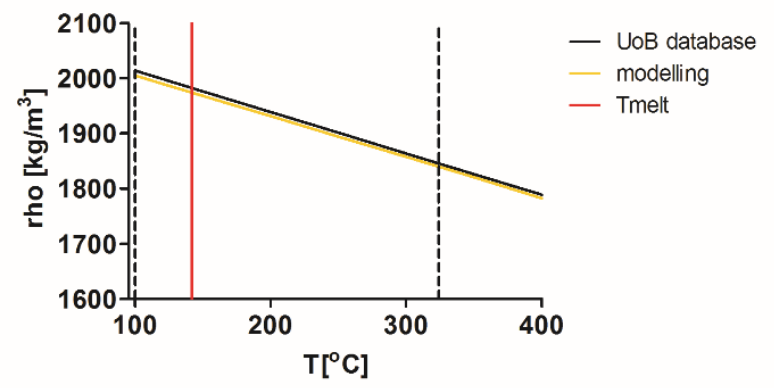

Figure 4 - Example of the simulation in Aspen+ including the hybrid approach with HITEC. In this are presented the literature published correlation (black), between its validity range (dashed vertical lines); the melting point temperature (red vertical line); Aspen ${ }^{+}$prediction with pure salts properties published in literature as input (yellow); Aspen ${ }^{+}$prediction with hybrid property approach for pure salts as input (blue).

The ability to reproduce the thermo-physical properties of the baseline commercial salt mixtures, using the UoB database of pure salts, gave high confidence in estimating thermo-physical properties not yet published in the literature, for both the remaining commercial salt mixtures as well as their alternative weight compositions. This allowed to proceed with the second screening process, which was the evaluation of the overall physical properties calculated in the temperature range of interest $\left(100-400^{\circ} \mathrm{C}\right)$. The most relevant of these primary properties being, the volumetric heat capacity, calculated from specific heat capacity and density as:

$$
c_{v}=c_{p} \cdot \rho
$$

Table 10 shows the values of the volumetric heat capacities for the baseline commercial salt mixtures averaged over the selected temperature range. It is evident how the chloride-based mixtures give lower volumetric heat capacities when compared to the nitrates-based mixtures (1.71-2.19 vs. 2.78-3.14 $\left.\mathrm{MJ} / \mathrm{m}^{3} \mathrm{~K}\right)$.

Table 10 - Averaged volumetric heat capacity of the baseline commercial salt mixtures over the selected temperature range of interest $\left(100-400^{\circ} \mathrm{C}\right)$.

\begin{tabular}{lr}
\hline Salt mixtures & $c_{v}\left[M J /\left(m^{3} \mathrm{~K}\right)\right]$ \\
\hline Solar Salt & 2.89 \\
HITEC & 3.01 \\
NaCl-AlCl3 & 2.19 \\
KCl-AlCl3 & 1.71 \\
KCl-ALCl3-NaCl & 1.98 \\
LiNaK & 2.89 \\
LiK & 2.78 \\
Quaternary & 2.97 \\
HITEC XL & 2.94 \\
CaLiNaK & 3.14 \\
\hline
\end{tabular}

Table 11 provides the remaining primary properties for the baseline commercial salt mixtures, such as density, specific heat capacity, viscosity, thermal conductivity, that were averaged over the selected temperature range. These averaged values aided the down-selection process for the salt mixtures. In addition to this, the specific cost was also considered, which was calculated by combining the pure salt 
costs according to their concentrations. Note that, due to the vastly differing cost information of aluminium chloride, the wholesale cost of chloride-based mixtures cannot be estimated reliably at this stage.

Table 11 - Critical properties of the baseline commercial salt mixtures used in the down-selection process. The values are averaged over the temperature range of interest $\left(100-400^{\circ} \mathrm{C}\right)$.

\begin{tabular}{llllll}
\hline $\begin{array}{l}\text { Salt } \\
\text { Name }\end{array}$ & $\begin{array}{c}\rho \\
{\left[\mathrm{kg} / \mathrm{m}^{3}\right]}\end{array}$ & $\begin{array}{c}c_{p} \\
{[\mathrm{~kJ} / \mathrm{kg} \mathrm{K}]}\end{array}$ & $\begin{array}{c}\mu \\
{[\mathrm{mPa} * \mathrm{~s}]}\end{array}$ & $\begin{array}{c}\lambda \\
{[\mathrm{W} / \mathrm{m} \mathrm{K}]}\end{array}$ & $\begin{array}{l}\text { Cost } \\
{[\$ / \mathrm{kg}]}\end{array}$ \\
\hline Solar Salt & 1897 & 1.50 & 0.02 & 0.46 & 0.5 \\
HITEC & 1916 & 1.49 & 5.64 & 0.46 & 0.9 \\
NaCl-AlCl3 & 1645 & 1.32 & 1.52 & 0.09 & \\
KCl-AlCl3 & 1825 & 0.93 & 0.96 & 0.07 & \\
KCl-AlCl3-NaCl & 1754 & 1.16 & 1.98 & 0.09 & \\
LiNaK & 1872 & 1.55 & 4.59 & 0.41 & 1.1 \\
LiK & 1867 & 1.48 & 5.07 & 0.39 & 1.3 \\
Quaternary & 1904 & 1.56 & 6.87 & 0.43 & 0.9 \\
HITEC XL & 2002 & 1.45 & 31.37 & 0.52 & 1.1 \\
CaLiNaK & 1917 & 1.65 & 66.13 & 0.50 & 1.1 \\
\hline
\end{tabular}

In Table 2, it was shown that chloride-based salts give favourable melting point temperature of $<130^{\circ} \mathrm{C}$. However, from Table 11, it is evident that they are associated with unfavourable thermo-physical properties. In fact, they offer lower density $\left(1645-1825 \mathrm{vs} .1867-2002 \mathrm{~kg} / \mathrm{m}^{3}\right)$, lower specific heat $(0.93-$ 1.32 vs. $1.48-1.56 \mathrm{~kJ} / \mathrm{kg} \mathrm{K})$ and lower thermal conductivity $(0.07-0.09$ vs. $0.39-0.52 \mathrm{~W} / \mathrm{m} \mathrm{K})$ with respect to the nitrates-based salt mixtures. The improvement provided by the lower viscosity (0.96-1.98 vs. $4.59-66.13 \mathrm{mPa} \bullet \mathrm{s}$ ) is considered to be not beneficial to counterbalance the other negative properties. For these reasons, the chloride-based salt mixtures were disregarded from further consideration.

The screening process based on melting temperatures (Table 2) and thermo-physical properties (Table 10 and Table 11), resulted in the selection of HITEC, LiNaK, LiK, Quaternary, CaLiNaK as the 5 baseline commercial salt mixtures for further investigation. Note that, HITEC XL was also disregarded from further investigations, since simulating salt mixture with high wt $\%(>45 \%)$ of calcium nitrate were associated with elevated error $(>40 \%)$ due to the scarcity of published data.

\subsection{Parametric Analysis}

In this section, the parametric analysis performed by varying the composition of the 5 down selected baseline commercial salts are presented. The objective of this analysis was to investigate if alternative mixtures concentrations exists that could potentially be beneficial for the chosen LAES application. From each one of the selected baseline commercial salt mixtures, the wt $\%$ of each pure salt constituent in the mixture was varied. These mixtures are given in Table 12, were name-1 corresponds to the commercial composition and name-2,3,4 etc. corresponds to alternative compositions under investigation.

In order to evaluate the alternative compositions, a unique feasibility parameter considering the relevant criteria for the screening process was needed. Therefore the parameter, Performance and System Index (PSI), represented by equation 2 is proposed:

$$
P S I=f_{1} \frac{\mu_{r e f}}{\mu_{i}}+f_{2} \frac{\lambda_{i}}{\lambda_{\text {ref }}}+f_{3} \frac{c_{v, i}}{c_{v, r e f}}+f_{4} \frac{\$_{r e f}}{\$_{i}}
$$

where the subscript $i$ indicates the salt mixture under examination and the subscript $r e f$ indicates the baseline commercial composition reported in Table 11 used as benchmark. The weighting factors $f_{1}, f_{2}, f_{3}, f_{4}$ were chosen between 0.2-0.4 to reflect the importance on the overall feasibility of the thermal store using viscosity $\left(f_{1}=0.2\right)$, thermal conductivity $\left(f_{2}=0.2\right)$, volumetric heat capacity $\left(f_{3}=0.4\right)$ and costs $\left(f_{4}=0.2\right)$, respectively. Therefore, preferred alternative compositions would have lower viscosity and cost, and higher thermal conductivity and volumetric heat capacity.

Utilising equation 2, the reference mixture gave a unitary PSI value, whereas the alternative mixtures gave a PSI value greater than 1 (favourable) or lesser than 1 (unfavourable). This simplified the evaluation of alternative compositions. Table 12 details the different permutation of alternative salt 
compositions and their resulting PSI values when utilising the averaged thermo-physical values from Table 11. Note that, when considering CaLiNaK, the calcium nitrate concentration was limited to $25 \%$ wt., since higher concentrations were associated with elevated errors. In conclusion of this parametric analysis (Table 12), there existed 42 out of 70 alternative mixtures for the 5 down selected baseline commercial mixtures that provided a PSI value greater than 1, and were therefore promising for further investigation.

Table 12 - PSI value of the baseline commercial compositions and alternative compositions utilising the averaged thermo-physical values over the selected temperature range.

\begin{tabular}{|c|c|c|c|c|c|c|c|c|c|c|}
\hline ID & NaNO3 & KNO3 & LiNO3 & $\mathrm{NaNO} 2$ & $\mathrm{Ca}(\mathrm{NO} 3) 2$ & $\begin{array}{c}\text { Cost } \\
{[\$ / \mathrm{kg}]}\end{array}$ & $\begin{array}{c}\boldsymbol{\mu} \\
{[\mathrm{mPa} \text { s] }}\end{array}$ & $\begin{array}{c}\lambda \\
{[\mathrm{W} / \mathrm{m} \mathrm{K}]}\end{array}$ & $\begin{array}{c}\boldsymbol{c}_{\boldsymbol{v}} \\
{\left[\mathrm{MJ} / \mathrm{m}^{3} \mathrm{~K}\right]}\end{array}$ & PSI \\
\hline LiK-1 & & 68 & 32 & & & 0.55 & 6.84 & 0.40 & 2.78 & 1.21 \\
\hline LiK-2 & & 48 & 52 & & & 0.51 & 7.20 & 0.43 & 3.03 & 1.13 \\
\hline LiK-3 & & 28 & 72 & & & 0.47 & 7.53 & 0.46 & 3.27 & 1.06 \\
\hline LiK-4 & & 8 & 92 & & & 0.43 & 7.82 & 0.51 & 3.50 & 1.00 \\
\hline LiK-5 & & 88 & 12 & & & 0.59 & 6.45 & 0.38 & 2.53 & 0.94 \\
\hline HIT-1 & 7 & 50 & & 43 & & 0.48 & 8.96 & 0.43 & 3.14 & 1.00 \\
\hline HIT-2 & 33 & 34 & & 33 & & 0.47 & 6.47 & 0.44 & 3.10 & 1.07 \\
\hline HIT-3 & 3 & 64 & & 33 & & 0.53 & 8.14 & 0.40 & 2.88 & 0.95 \\
\hline HIT-4 & 3 & 34 & & 63 & & 0.45 & 10.28 & 0.45 & 3.31 & 1.04 \\
\hline HIT-5 & 63 & 4 & & 33 & & 0.40 & 5.32 & 0.49 & 3.32 & 1.21 \\
\hline HIT-6 & 63 & 34 & & 3 & & 0.48 & 4.16 & 0.43 & 2.89 & 1.14 \\
\hline HIT-7 & 33 & 64 & & 3 & & 0.54 & 4.99 & 0.40 & 2.66 & 1.02 \\
\hline HIT-8 & 33 & 4 & & 63 & & 0.39 & 8.16 & 0.51 & 3.52 & 1.16 \\
\hline LNK-1 & 18 & 52 & 30 & 30 & & 0.70 & 5.99 & 0.42 & 2.89 & 1.00 \\
\hline LNK-2 & 33 & 34 & 33 & 33 & & 0.68 & 5.48 & 0.44 & 3.04 & 1.05 \\
\hline LNK-3 & 3 & 64 & 33 & 33 & & 0.74 & 6.71 & 0.40 & 2.82 & 0.95 \\
\hline LNK-4 & 3 & 34 & 63 & 63 & & 0.85 & 7.24 & 0.45 & 3.18 & 0.99 \\
\hline LNK-5 & 63 & 4 & 33 & 33 & & 0.61 & 4.62 & 0.49 & 3.26 & 1.16 \\
\hline LNK-6 & 63 & 34 & 3 & 3 & & 0.50 & 4.11 & 0.43 & 2.88 & 1.17 \\
\hline LNK-7 & 33 & 64 & 3 & 3 & & 0.56 & 4.91 & 0.40 & 2.66 & 1.05 \\
\hline LNK-8 & 33 & 4 & 63 & 63 & & 0.79 & 5.99 & 0.50 & 3.40 & 1.08 \\
\hline QUT-1 & 14.2 & 50.5 & 17.5 & 17.8 & & 0.61 & 6.14 & 0.42 & 2.96 & 1.00 \\
\hline QUT-2 & 25 & 25 & 25 & 25 & & 0.60 & 5.94 & 0.46 & 3.24 & 1.07 \\
\hline QUT-3 & 45 & 5 & 25 & 25 & & 0.56 & 5.26 & 0.50 & 3.38 & 1.14 \\
\hline QUT-4 & 45 & 25 & 5 & 25 & & 0.48 & 4.91 & 0.45 & 3.14 & 1.14 \\
\hline QUT-5 & 45 & 25 & 25 & 5 & & 0.61 & 5.02 & 0.45 & 3.10 & 1.07 \\
\hline QUT-6 & 5 & 45 & 25 & 25 & & 0.64 & 6.79 & 0.43 & 3.09 & 1.00 \\
\hline QUT-7 & 5 & 25 & 45 & 25 & & 0.72 & 7.12 & 0.47 & 3.33 & 1.02 \\
\hline QUT-8 & 5 & 25 & 25 & 45 & & 0.59 & 7.03 & 0.47 & 3.38 & 1.07 \\
\hline QUT-9 & 25 & 5 & 45 & 25 & & 0.67 & 6.27 & 0.51 & 3.48 & 1.08 \\
\hline QUT-10 & 25 & 5 & 25 & 45 & & 0.55 & 6.18 & 0.51 & 3.52 & 1.14 \\
\hline QUT-11 & 25 & 45 & 5 & 25 & & 0.52 & 5.57 & 0.43 & 2.99 & 1.06 \\
\hline QUT-12 & 25 & 45 & 25 & 5 & & 0.65 & 5.68 & 0.43 & 2.95 & 1.00 \\
\hline QUT-13 & 25 & 25 & 5 & 45 & & 0.47 & 5.84 & 0.46 & 3.28 & 1.15 \\
\hline QUT-14 & 25 & 25 & 45 & 5 & & 0.73 & 6.04 & 0.46 & 3.19 & 1.01 \\
\hline QUT-15 & 65 & 25 & 5 & 5 & & 0.49 & 4.16 & 0.45 & 3.00 & 1.15 \\
\hline QUT-16 & 65 & 5 & 25 & 5 & & 0.57 & 4.50 & 0.49 & 3.24 & 1.14 \\
\hline QUT-17 & 65 & 5 & 5 & 25 & & 0.44 & 4.39 & 0.49 & 3.29 & 1.23 \\
\hline QUT-18 & 5 & 65 & 5 & 25 & & 0.56 & 6.41 & 0.40 & 2.85 & 0.99 \\
\hline QUT-19 & 5 & 65 & 25 & 5 & & 0.69 & 6.53 & 0.40 & 2.80 & 0.93 \\
\hline QUT-20 & 25 & 65 & 5 & 5 & & 0.57 & 5.30 & 0.40 & 2.70 & 0.99 \\
\hline QUT-21 & 25 & 5 & 65 & 5 & & 0.80 & 6.37 & 0.51 & 3.43 & 1.04 \\
\hline QUT-22 & 5 & 5 & 65 & 25 & & 0.79 & 7.43 & 0.52 & 3.56 & 1.04 \\
\hline QUT-23 & 5 & 25 & 65 & 5 & & 0.84 & 7.22 & 0.47 & 3.29 & 0.97 \\
\hline QUT-24 & 5 & 25 & 5 & 65 & & 0.46 & 6.95 & 0.47 & 3.42 & 1.15 \\
\hline QUT-25 & 25 & 5 & 5 & 65 & & 0.42 & 6.10 & 0.51 & 3.57 & 1.24 \\
\hline QUT-26 & 5 & 5 & 25 & 65 & & 0.54 & 7.27 & 0.52 & 3.65 & 1.15 \\
\hline CAL-1 & 16.8 & 45 & 24.6 & & 13.6 & 0.56 & 3.58 & 0.41 & 3.36 & 1.00 \\
\hline CAL-2 & 25 & 25 & 25 & & 25 & 0.55 & 2.30 & 0.43 & 3.83 & 1.16 \\
\hline CAL-3 & 45 & 5 & 25 & & 25 & 0.59 & 2.12 & 0.46 & 3.97 & 1.19 \\
\hline CAL-4 & 45 & 25 & 5 & & 25 & 0.47 & 1.79 & 0.42 & 3.74 & 1.25 \\
\hline CAL-5 & 45 & 25 & 25 & & 5 & 0.64 & 4.15 & 0.45 & 3.23 & 0.94 \\
\hline CAL-6 & 5 & 45 & 25 & & 25 & 0.51 & 2.51 & 0.40 & 3.70 & 1.13 \\
\hline CAL-7 & 5 & 25 & 45 & & 25 & 0.62 & 2.93 & 0.43 & 3.92 & 1.09 \\
\hline
\end{tabular}




\begin{tabular}{lccccccccc}
\hline CAL-9 & 25 & 5 & 45 & 25 & 0.67 & 2.67 & 0.47 & 4.06 & 1.12 \\
CAL-11 & 25 & 45 & 5 & 25 & 0.43 & 1.93 & 0.40 & 3.60 & 1.23 \\
CAL-12 & 25 & 45 & 25 & 5 & 0.60 & 4.59 & 0.42 & 3.09 & 0.92 \\
CAL-14 & 25 & 25 & 45 & 5 & 0.72 & 5.04 & 0.45 & 3.34 & 0.91 \\
CAL-15 & 65 & 25 & 5 & 5 & 0.56 & 3.41 & 0.44 & 3.13 & 0.98 \\
CAL-16 & 65 & 5 & 25 & 5 & 0.68 & 3.79 & 0.48 & 3.38 & 0.97 \\
CAL-17 & 65 & 5 & 5 & 25 & 0.51 & 1.67 & 0.45 & 3.88 & 1.28 \\
CAL-18 & 5 & 65 & 5 & 25 & 0.39 & 2.10 & 0.38 & 3.46 & 1.22 \\
CAL-19 & 5 & 65 & 25 & 5 & 0.56 & 5.13 & 0.40 & 2.94 & 0.89 \\
CAL-20 & 25 & 65 & 5 & 5 & 0.48 & 4.41 & 0.40 & 2.88 & 0.94 \\
CAL-21 & 25 & 5 & 65 & 5 & 0.83 & 5.47 & 0.50 & 3.58 & 0.93 \\
CAL-22 & 5 & 5 & 65 & 25 & 0.74 & 3.34 & 0.47 & 4.14 & 1.08 \\
CAL-23 & 5 & 25 & 65 & 5 & 0.79 & 6.08 & 0.46 & 3.44 & 0.89 \\
\hline
\end{tabular}

\section{Melting Point Experimental Investigation}

A thermo-physical property that cannot be estimated by the chosen software was the melting point of the alternative salt mixtures. Hence, the presented experimental investigation was focused on measuring the melting point of the most promising (PSI $>1$ ) alternative compositions resulting from the parametric analysis (Table 12).

Alternative salt mixture concentrations were prepared using the pure salts $\left(\mathrm{KNO}_{3}, \mathrm{NaNO}_{3}, \mathrm{NaNO}_{2}\right.$, $\mathrm{LiNO}_{3}, \mathrm{CaNO}_{3} \bullet 4 \mathrm{H}_{2} \mathrm{O}, 99 \%$ purity, Merck ${ }^{\circledR}$ ). To ensure fine homogenous mixture, mass fractions were prepared using the Kern weighing scale (resolution $0.1 \mathrm{mg}$ ) and mixed using the Camlab vortex mixer. To limit errors relating to small weight fractions of pure salts, the minimum quantity prepared of alternative salt mixture was 5 grams.

For measuring the melting point, the Stuart ${ }^{\circledR} \mathrm{SMP} 3$ was used (accuracy $\pm 0.5^{\circ} \mathrm{C}$ ). This allowed the simultaneous testing of three capillary samples (OD/ID $1.9 \mathrm{~mm} / 1.3 \mathrm{~mm}$ ) with a fine control of the heating ramp rate. During testing of each mixture, a fast $5^{\circ} \mathrm{C} / \mathrm{min}$ ramp rate was applied until the plateau temperature was reached, which was set at $30^{\circ} \mathrm{C}$ lower than the melting temperature of the baseline commercial salt mixture. Once the plateau temperature was reached, a slower $1{ }^{\circ} \mathrm{C} / \mathrm{min}$ ramp rate was applied. In order to gain enough precision, three tests were conducted for each salt mixture and the mean values were taken.

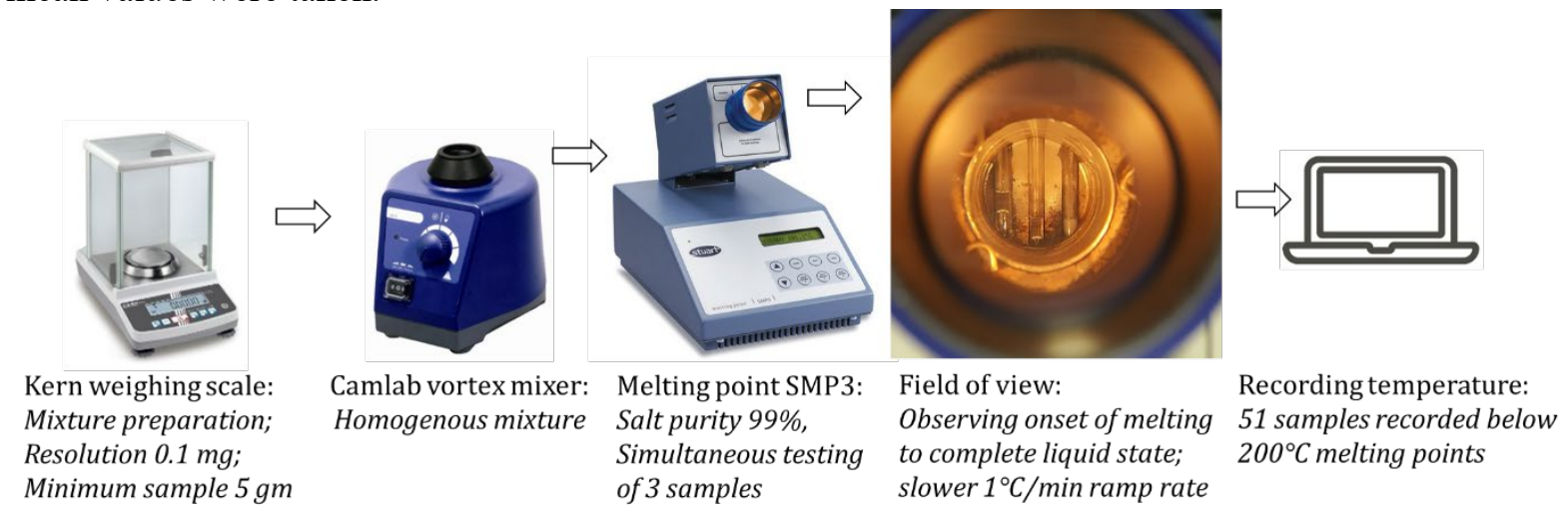

Figure 5 - Experimental set-up and description: Fine homogenous salt mixture ensured using the Kern weighing scale and Camlab vortex mixer. The sample is inserted in SMP3 for recording the melting temperature observed via the field of view.

The melting temperature was calculated, using a standard approach [35]:

$$
T_{m}=\frac{T_{m, 1}+T_{m, 2}}{2}
$$

where $T_{m, 1}$ is the temperature at which the onset of melting was observed (e.g. refer Figure 7a) and $T_{m, 2}$ is the temperature at which the samples were noted to be in a complete liquid state (e.g. refer Figure $7 \mathrm{c}$ ). 
Particular attention was given to avoid air gaps and to ensure equal quantity of salt mixtures inside the tubes. The small tube sizes assured a favourable heat transfer to the salt mixtures due to the low thermal inertia. However, on occasions, this hindered the homogeneity of the sample, as some single salt clusters were observed separating from the salt mixture during testing. In Figure 7, images show the melting sequence for $\mathrm{CaLiNaK}$ using the field of view given by the experimental device. The sequence was captured at every $5^{\circ} \mathrm{C}$ for visual inspection, but has been omitted for brevity.

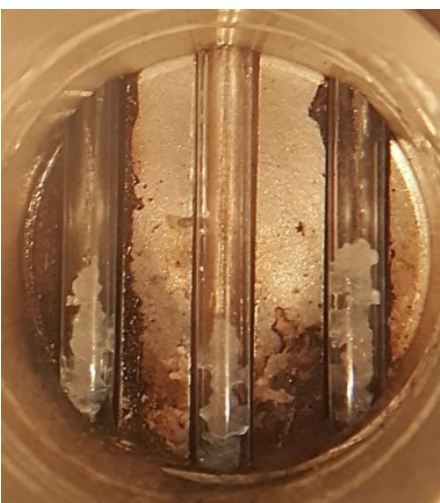

(a) $60^{\circ} \mathrm{C}$ - Melting Started

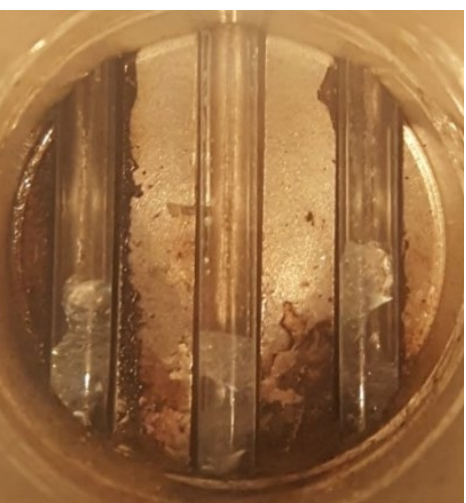

(b) $95^{\circ} \mathrm{C}$ - Partial Melting

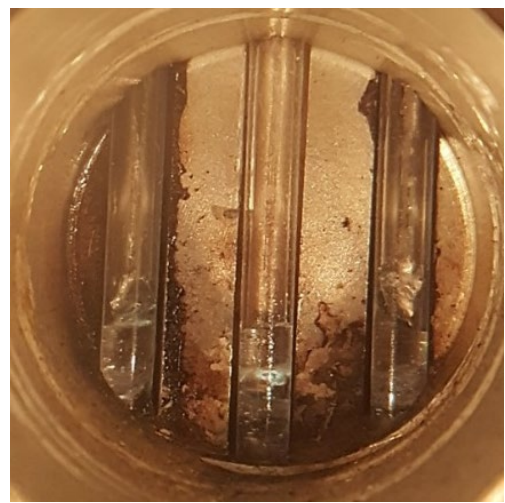

(c) $125^{\circ} \mathrm{C}$ - Melting Completed

Figure 6 - Example of a melting temperature test sequence during testing of CaLiNaK commercial composition using SMP3.

Firstly, a validation of the experimental procedure was performed, with the aim of reproducing the melting point of the baseline commercial salt mixtures reported in the literature. The experimental data for validation is presented in Table 13 . HITEC, $\mathrm{LiK}$ and $\mathrm{LiNaK}$ results were reproduced within $1-3^{\circ} \mathrm{C}$ of the published values. However, a greater discrepancy was noted for the quaternary mixtures, with errors of $11-19^{\circ} \mathrm{C}$. This may be attributed to a three-fold challenge. Firstly, the precision required for the individual components (e.g. wt $\% 14.2$ of NaNO3 in Quaternary). Secondly, the complexity associated with an increased number of individual mixture components. Finally, due to the individual components purity being $99 \%$ (rather than $99.99 \%$ ), to ensure an economical molten salt thermal store solution for the considered LAES application.

Table 13 - Experimental validation of melting point temperature for the baseline commercial salt mixtures (all values are in $\left.{ }^{\circ} \mathrm{C}\right)$.

\begin{tabular}{lrrrrrrr}
\hline Salt Name & & Tube 1 & Tube 2 & Tube 3 & $T_{m}$ & $\Delta \mathrm{T}$ & $\sigma$ \\
\hline \multirow{3}{*}{ HITEC } & Test 1 & 143 & 146 & 144 & & & \\
& Test 2 & 138 & 138 & 148 & 143 & 1 & 3.2 \\
& Test 3 & 141 & 144 & 144 & & & \\
\hline \multirow{2}{*}{ LiK } & Test 1 & 138 & 132 & 130 & & & \\
& Test 2 & 133 & 132 & 129 & 132 & -1 & 2.6 \\
& Test 3 & 131 & 130 & 129 & & & \\
\hline \multirow{3}{*}{ LiNaK } & Test 1 & 122 & 123 & 125 & & & \\
& Test 2 & 127 & 123 & 123 & 123 & 3 & 1.9 \\
& Test 3 & 120 & 123 & 125 & & & \\
\hline \multirow{3}{*}{ Quaternary } & Test 1 & 115 & 122 & 126 & & & \\
& Test 2 & 117 & 116 & 114 & 118 & -19 & 3.5 \\
& Test 3 & 117 & 118 & 118 & & & \\
\hline \multirow{2}{*}{ CaLiNaK } & Test 1 & 92 & 93 & 91 & & & \\
& Test 2 & 84 & 81 & 86 & 86 & -11 & 6.5 \\
& Test 3 & 83 & 92 & 72 & & & \\
\hline
\end{tabular}

Following the validation of the experimental procedure, two types of alternative salt mixtures were tested: mixtures offering noticeably higher PSI values and mixtures with comparable composition to the baseline commercial salt mixtures (but with PSI values $>1$ ). In Table 14, the summary of the experimental results are reported. In some cases, testing was discontinued if the onset of melting was not observed below $200^{\circ} \mathrm{C}$, thus making the salt not suitable for the considered LAES application. 
Table 14 - Summary of melting point of alternative salt mixtures (- means that the onset of melting was not observed below $200^{\circ} \mathrm{C}$ ).

\begin{tabular}{lllrrr}
\hline Salt Name & ID & PSI & $T_{m}\left[{ }^{\circ} \mathrm{C}\right]$ & $\Delta T\left[{ }^{\circ} \mathrm{C}\right]$ & $\sigma$ \\
\hline \multirow{4}{*}{ HITEC } & 5 & 1.21 & - & - & - \\
& 8 & 1.16 & - & - & - \\
& 2 & 1.07 & 162 & 20 & 5.7 \\
& 4 & 1.04 & 172 & 30 & 3.3 \\
\hline LiK & 3 & 1.13 & - & - & - \\
\hline \multirow{5}{*}{ LiNaK } & 5 & 1.16 & - & - & - \\
& 6 & 1.17 & 182 & 62 & 3 \\
& 2 & 1.05 & 137 & 17 & 2.3 \\
& 7 & 1.05 & - & - & - \\
\hline \multirow{5}{*}{ Quaternary } & 17 & 1.23 & 206 & 107 & 2 \\
& 25 & 1.24 & 175 & 76 & 2.3 \\
& 11 & 1.06 & 145 & 46 & 2.5 \\
\multirow{2}{*}{ CaLiNaK } & 2 & 1.07 & 160 & 61 & 3.1 \\
& 4 & 1.25 & 95 & 20 & 7.9 \\
& 17 & 1.28 & - & - & - \\
& 11 & 1.23 & 105 & 30 & 7.2 \\
\hline
\end{tabular}

Considering Table 13 and Table 14, it can be noted that most of the alternative salt mixtures associated with high PSI values (1.13-1.28) resulted in a noticeable increase in the melting point temperature (62$107^{\circ} \mathrm{C}$ ) with respect to the baseline mixture. The alternative salt mixtures associated with medium PSI values (1.04-1.07) resulted in a compromised solution, with limited increase in melting point temperature $\left(17-46^{\circ} \mathrm{C}\right)$ with respect to the baseline mixture. This was because the medium PSI value mixtures had compositions that were comparable to the baseline commercial salt mixtures. More importantly, two alternative salt mixtures ( $\mathrm{CaLiNaK} 4$ and 11), which were associated with high PSI values (1.25 and 1.23), were identified to give preferred trade-off, resulting in comparable melting point temperature $\left(+9^{\circ} \mathrm{C}\right.$ and $\left.+19^{\circ} \mathrm{C}\right)$ with respect to the baseline mixture.

To compare the different salt mixtures using a common feasibility indicator, a modified version of the performance and system index, called the Pseudo Performance Index (PPI), is proposed as defined in equation 4. Using PPI, the different mixtures were evaluated against a 'hypothetical' mixture, which was created using the best individual thermo-physical and cost values amongst the 5 baseline commercial salt mixtures. In other words, this hypothetical salt mixture had the lowest viscosity and cost, together with the highest thermal conductivity and volumetric heat capacity.

$$
P P I=f_{1} \frac{\mu_{\min }}{\mu_{i}}+f_{2} \frac{\lambda_{i}}{\lambda_{\max }}+f_{3} \frac{c_{v, i}}{c_{v, \max }}+f_{4} \frac{\$_{\min }}{\$_{i}}
$$

The subscript $i$, represents any tested salt mixtures, whereas the subscripts max and $\min$, represent the hypothetical salt, utilising the best individual values amongst the 5 baseline commercial salt mixtures. Hence, the hypothetical salt results in a maximum PPI value of 1 , whereas the alternative and baseline commercial salt mixtures result in a value lower than 1. Similar to the performance and system index, the highest weight factor was associated with the volumetric heat capacity for the considered case.

The experimental melting temperatures (Table 13 and Table 14) and the common feasibility indicator PPI values (Table 15), allowed the creation of synoptic maps, as shown in Figure 8 and Figure 9, aiding the identification of the desired salt mixtures. When considering the characteristics of the LAES application, the green dashed area in Figure 8 and Figure 9 represent the preferred trade-off region between performance index value and melting point. The two new salt mixtures CaLiNaK 4 and 11 were in this preferred trade-off region.

In summary, the proposed and implemented molten salt selection methodology in this work has identified two alternative salt mixtures, $\mathrm{CaLiNaK} 4$ and 11 (Table 15), which provide noticeably higher PPI values (0.56-0.55 vs. 0.41$)$ and comparable melting points $\left(95-105^{\circ} \mathrm{C}\right.$ vs. $\left.86^{\circ} \mathrm{C}\right)$ to $\mathrm{CaLiNaK} 1$. When considering the melting temperature threshold in the region of $100^{\circ} \mathrm{C}$, the $34-37 \%$ increase in the performance indicator value results in an improved thermal store option. Hence, CaLiNaK 4 and 11 must be considered as potential alternatives for improving the cost-effectiveness of the considered LAES application. 
Table 15 - Melting temperature and PPI values for the baseline commercial and alternative salt mixtures.

\begin{tabular}{lllr}
\hline & ID & PPI & $T_{\text {melt }}\left[{ }^{\circ} \mathrm{C}\right]$ \\
\hline \multirow{4}{*}{ HITEC } & 1 & 0.38 & 142 \\
& 5 & 0.47 & 330 \\
& 8 & 0.46 & 330 \\
& 2 & 0.41 & 162 \\
& 4 & 0.40 & 172 \\
\hline \multirow{4}{*}{ Quaternary } & 1 & 0.35 & 118 \\
& 17 & 0.46 & 206 \\
& 25 & 0.46 & 175 \\
& 11 & 0.39 & 144 \\
\multirow{4}{*}{ LiNaK } & 2 & 0.38 & 160 \\
& 1 & 0.34 & 120 \\
& 5 & 0.40 & 330 \\
& 6 & 0.41 & 182 \\
\multirow{2}{*}{ LiK } & 2 & 0.36 & 137 \\
& 7 & 0.36 & 334 \\
\hline \multirow{4}{*}{ CaLiNaK } & 1 & 0.35 & 133 \\
& 3 & 0.41 & 330 \\
\hline & 1 & 0.41 & 86 \\
& 4 & 0.56 & 95 \\
& 17 & 0.58 & 170 \\
& 11 & 0.55 & 105 \\
\hline
\end{tabular}

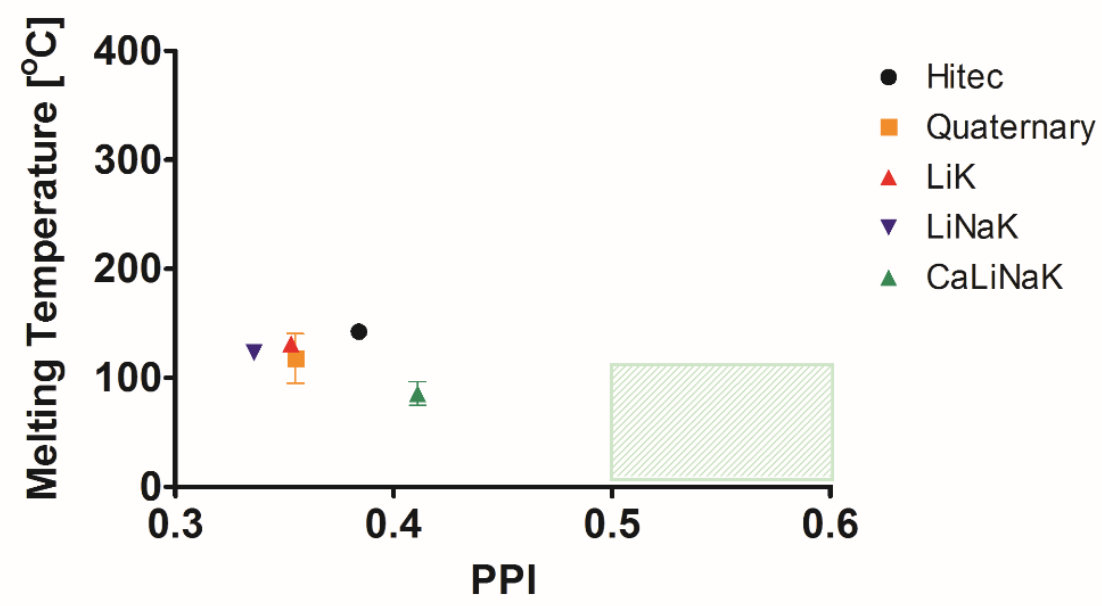

Figure 7 - Melting Temperature vs PPI map, for baseline commercial salt mixtures. The green dashed area is the preferred trade-off region between melting temperature and performance. 


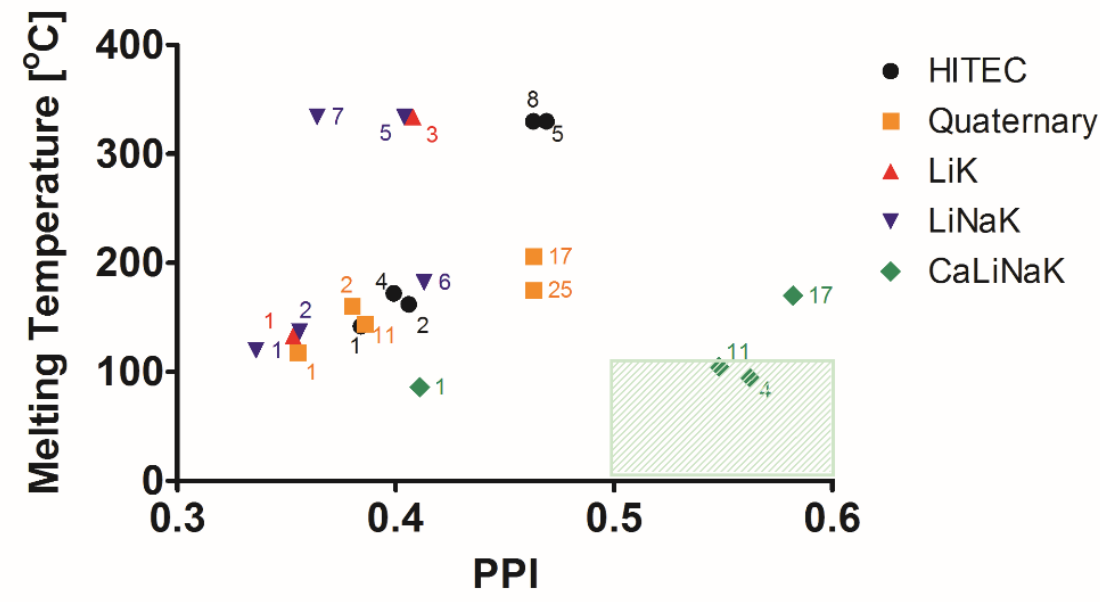

Figure 8 - Melting temperature vs. PPI map, including all the considered alternative salt mixtures. The green dashed area is the preferred trade-off region between melting temperature and performance.

\section{Conclusion}

This work was primarily focused on the identification and evaluation of alternative nitrate-based molten salt mixtures as common thermal medium for thermal storage and heat transfer fluid in the $100-400^{\circ} \mathrm{C}$ range for a Liquid Air Energy Storage application. The significant conclusions of the present investigation are as follows:

1. A database of pure salts and molten salt mixtures (Reported in Table 1 to Table 8) was created by integrating various literature correlations, coupling these with appropriate Aspen ${ }^{+}$property packages and extending the validity range of selected properties using the considered hybrid approach (As detailed by Figure 3). The additional contributions to the database, resulting from the considered hybrid approach, are reported in Table 9.

2. Two numerical indicators, the Performance and System Index (PSI, equation 2), and its variant, the Pseudo Performance Index (PPI, equation 4), were proposed and utilised in the thermophysical screening of 70 molten salt mixtures.

3. Experimental investigations were conducted to identify the melting point (Reported in Table 13 and Table 14) of 16 new salt mixtures in the $100-200^{\circ} \mathrm{C}$ range which could increase the feasibility of the thermal store.

4. Two new salt mixtures (CaLiNaK 4 and 11) were identified as preferred alternatives, resulting in higher PPI values (0.56-0.55 vs. 0.41$)$ with nominal increase in the melting points $(95-105$ vs. $86^{\circ} \mathrm{C}$ ) when compared to the baseline commercial CaLiNaK mixture.

In summary, the proposed molten salt methodology was proven to be an effective and versatile tool in identifying preferred salt mixtures (e.g. CaLiNaK 4 and 11 providing 34-37\% improvement over the baseline commercial salt), and hence, this methodology can be adapted for comparable applications.

\section{Acknowledgments}

This work was funded by INNOVATE UK "Development of High Grade Heat Storage for integration with Liquid Air Energy Storage" (Ref 133465) project. The authors would like to acknowledge the support of the industrial partner, Highview Power Storage Limited (Johnny Cochrane and Edward Scrase), and the School of Pharmacy and Biomolecular Sciences (Dr. Petra Kristova).

\section{References}

[1] Ameel B, T'Joen C, De Kerpel K, De Jaeger P, Huisseune H, Van Belleghem M, De Paepe M. Thermodynamic analysis of energy storage with a liquid air Rankine cycle. Applied Thermal Engineering 2013;52:130-40. doi:10.1016/j.applthermaleng.2012.11.037.

[2] Peng H, Shan X, Yang Y, Ling X. A study on performance of a liquid air energy storage system with packed bed units. Applied Energy 2018;211:126-35. doi:10.1016/j.apenergy.2017.11.045. 
[3] Morgan R, Nelmes S, Gibson E, Brett G. Liquid air energy storage - Analysis and first results from a pilot scale demonstration plant. Applied Energy 2015;137:845-53. doi:10.1016/j.apenergy.2014.07.109.

[4] Xie C, Hong Y, Ding Y, Li Y, Radcliffe J. An economic feasibility assessment of decoupled energy storage in the UK: With liquid air energy storage as a case study. Applied Energy 2018;225:244-57. doi:10.1016/j.apenergy.2018.04.074.

[5] She X, Peng X, Nie B, Leng G, Zhang X, Weng L, Tong L, Zheng L, Wang L, Ding Y. Enhancement of round trip efficiency of liquid air energy storage through effective utilization of heat of compression. Applied Energy 2017;206:1632-42. doi:10.1016/j.apenergy.2017.09.102.

[6] Tafone A, Borri E, Comodi G, van den Broek M, Romagnoli A. Liquid Air Energy Storage performance enhancement by means of Organic Rankine Cycle and Absorption Chiller. Applied Energy 2018;228:1810-21. doi:10.1016/j.apenergy.2018.06.133.

[7] Peng X, She X, Cong L, Zhang T, Li C, Li Y, Wang L, Tong L, Ding Y. Thermodynamic study on the effect of cold and heat recovery on performance of liquid air energy storage. Applied Energy 2018;221:86-99. doi:10.1016/j.apenergy.2018.03.151.

[8] Nunes VMB, Queirós CS, Lourenço MJV, Santos FJV, Nieto de Castro CA. Molten salts as engineering fluids - A review: Part I. Molten alkali nitrates. Applied Energy 2016;183:603-11. doi:10.1016/j.apenergy.2016.09.003.

[9] Serrano-ópez R, Fradera J, Cuesta-López S. Molten salts database for energy applications. Chemical Engineering and Processing - Process Intensification 2013;73:87-102. doi:10.1016/j.cep.2013.07.008.

[10] Piemonte V, Falco M De, Tarquini P, Giaconia A. Life Cycle Assessment of a high temperature molten salt concentrated solar power plant. Solar Energy 2011;85:1101-8. doi:10.1016/j.solener.2011.03.002.

[11] Adeoye JT, Amha YM, Poghosyan VH, Torchyan K, Arafat HA. Comparative LCA of Two Thermal Energy Storage Systems for Shams1 Concentrated Solar Power Plant: Molten Salt vs. Concrete. Journal of Clean Energy Technologies 2013;2:274-81. doi:10.7763/jocet.2014.v2.139.

[12] Bonk A, Sau S, Uranga N, Hernaiz M, Bauer T. Advanced heat transfer fluids for direct molten salt linefocusing CSP plants. Progress in Energy and Combustion Science 2018;67:1339-51. doi:10.1016/j.pecs.2018.02.002.

[13] Wu YT, Li Y, Ren N, Zhi RP, Ma CF. Experimental study on the thermal stability of a new molten salt with low melting point for thermal energy storage applications. Solar Energy Materials and Solar Cells 2018;176:181-9. doi:10.1016/j.solmat.2017.12.001.

[14] Zhang P, Cheng J, Jin Y, An X. Evaluation of thermal physical properties of molten nitrate salts with low melting temperature. Solar Energy Materials and Solar Cells 2018;176:36-41. doi:10.1016/j.solmat.2017.11.011.

[15] An XH, Cheng JH, Yin HQ, Xie LD, Zhang P. Thermal conductivity of high temperature fluoride molten salt determined by laser flash technique. International Journal of Heat and Mass Transfer 2015;90:872-7. doi:10.1016/j.ijheatmasstransfer.2015.07.042.

[16] Li C-J, Li P, Wang K, Emir Molina E. Survey of Properties of Key Single and Mixture Halide Salts for Potential Application as High Temperature Heat Transfer Fluids for Concentrated Solar Thermal Power Systems. AIMS Energy 2014;2:133-57. doi:10.3934/energy.2014.1.133.

[17] Kenisarin MM. High-temperature phase change materials for thermal energy storage. Renewable and Sustainable Energy Reviews 2010;14:955-70. doi:10.1016/j.rser.2009.11.011.

[18] Turnbull AG. The Thermal Conductivity of Molten Salts. Australian Journal of Applied Science 1961;59:324-9.

[19] Deem HW, Wood WD, Lucks CF. The Relationship Between Electrical and Thermal Conductivities of Titanium Alloys. Transactions of the Metallurgical Society of AIME 1958.

[20] O’Neil MJ. The Merck Index - An Encyclopedia of Chemicals, Drugs, and Biologicals. Cambridge, UK: RSC Publishing; 2013.

[21] Bradshaw RW, Siegel NP. MOLTEN NITRATE SALT DEVELOPMENT FOR THERMAL ENERGY STORAGE IN PARABOLIC TROUGH SOLAR POWER SYSTEMS. Proceedings of ES2008 Energy Sustainability 2008 August 10-14, 2008, Jacksonville, Florida USA, 2008.

[22] Vignarooban K, Xu X, Arvay A, Hsu K, Kannan AM. Heat transfer fluids for concentrating solar power systems - A review. Applied Energy 2015;146:383-96. doi:10.1016/j.apenergy.2015.01.125.

[23] Gil A, Medrano M, Martorell I, Lázaro A, Dolado P, Zalba B, Cabeza F L. State of the art on high temperature thermal energy storage for power generation. Part 1-Concepts, materials and modellization. Renewable and Sustainable Energy Reviews 2010;14:31-55. doi:10.1016/j.rser.2009.07.035.

[24] Bauer T, Breidenbach N, Eck M. Overview of Molten Salt Storage Systems and Material Development for Solar Thermal Power Plants. World Renewable Energy Forum 2012, 2012, p. 1-8. doi:234.

[25] Gimenez P, Fereres S. Effect of Heating Rates and Composition on the Thermal Decomposition of Nitrate Based Molten Salts. Energy Procedia 2015;69:654-62. doi:10.1016/j.egypro.2015.03.075.

[26] Kourkova L, Svoboda R, Sadovska G, Podzemna V, Kohutova A. Heat capacity of NaNO2. 
Thermochimica Acta 2009;491:80-3. doi:10.1016/j.tca.2009.03.005.

[27] Sádovská G, Honcová P, Pilař R, Oravová L, Honc D. Calorimetric study of calcium nitrate tetrahydrate and magnesium nitrate hexahydrate. Journal of Thermal Analysis and Calorimetry 2016;124:539-46. doi:10.1007/s10973-015-5159-y.

[28] Cordaro JG, Kruizenga AM, Altmaier R, Sampson M, Nissen A. Thermodynamic properties of molten nitrate salts 2011;1:2011.

[29] Janz GJ, Allen CB, Bansal NP, Murphy RM, Tomkins RPT. Physical properties data compilations relevant to energy storage, 2. Molten salts: Data on single and multi-component salt systems. vol. 80. 1979.

[30] Janz GJ, Tomkins RPT. Physical Properties Data Compilations Relevant to Energy Storage. IV. Molten Salts: Data on Additional Single and Multi-Component Salt Systems 1981.

[31] Chettri SK, Dev S, Ismail K. Density and Electrical Conductance of Calcium Nitrate Tetrahydrate + Acetamide Melt. Journal of Chemical and Engineering Data 1995;40:12-4. doi:10.1021/je00017a002.

[32] Zhao $\mathrm{CY}, \mathrm{Wu}$ ZG. Thermal property characterization of a low melting-temperature ternary nitrate salt mixture for thermal energy storage systems. Solar Energy Materials and Solar Cells 2011;95:3341-6. doi:10.1016/j.solmat.2011.07.029.

[33] Nunes VMB, Lourenço MJV, Santos FJV, Nieto De Castro CA. Viscosity of molten sodium nitrate. International Journal of Thermophysics 2006;27:1638-49. doi:10.1007/s10765-006-0119-1.

[34] Zhao QG, Hu CX, Liu SJ, Guo H, Wu YT. The thermal conductivity of molten NaNO3, KNO3, and their mixtures. Energy Procedia 2017;143:774-9. doi:10.1016/j.egypro.2017.12.761.

[35] McMurry J. Organic Chemistry, 8th Edition. Belmont, CA : Brooks Cole/Cengage Learning, 20122012. doi:10.1016/B0-08-043751-6/08302-X. 